\title{
Superabsorbent Hydrogels Based to Polyacrylamide/Cashew Tree Gum for the Controlled Release of Water and Plant Nutrients
}

\author{
Heldeney Rodrigues Sousa ${ }^{1}$, Idglan Sá Lima ${ }^{1}$, Lucas Matheus Lima Neris ${ }^{1}$, Albert Santos Silva ${ }^{1}$, \\ Ariane Maria Silva Santos Nascimento ${ }^{1}$, Francisca Pereira Araújo ${ }^{1}$, Rafael Felippe Ratke ${ }^{2}$ (D), \\ Durcilene Alves Silva ${ }^{1,3}$, Josy Anteveli Osajima ${ }^{1}\left(\mathbb{D}\right.$, Leilson Rocha Bezerra ${ }^{4}(\mathbb{D}$ \\ and Edson Cavalcanti Silva-Filho ${ }^{1, * \mathbb{D}}$
}

check for updates

Citation: Rodrigues Sousa, H.; Lima I.S.; Neris, L.M.L.; Silva, A.S.; Santos Nascimento, A.M.S.; Araújo, F.P. Ratke, R.F.; Silva, D.A.; Osajima, J.A.; Bezerra, L.R.; et al. Superabsorbent Hydrogels Based to

Polyacrylamide/Cashew Tree Gum for the Controlled Release of Water and Plant Nutrients. Molecules 2021 26, 2680. https://doi.org/10.3390/ molecules 26092680

Academic Editors:

Matthias Schnabelrauch and Roberta Cassano

Received: 4 March 2021

Accepted: 27 April 2021

Published: 3 May 2021

Publisher's Note: MDPI stays neutral with regard to jurisdictional claims in published maps and institutional affiliations.

Copyright: (C) 2021 by the authors Licensee MDPI, Basel, Switzerland. This article is an open access article distributed under the terms and conditions of the Creative Commons Attribution (CC BY) license (https:/ / creativecommons.org/licenses/by/ $4.0 /)$.
1 LIMAV, Interdisciplinary Laboratory for Advanced Materials, Piaui Federal University, Campus Universitário Ministro Petrônio Portella, Teresina 64049-550, Piaui, Brazil; tec.heldeney@ufpi.edu.br (H.R.S.);

i.dglan@hotmail.com (I.S.L.); luslima_neris@hotmail.com.br (L.M.L.N.); albeertsan@gmail.com (A.S.S.); ariane.am42@gmail.com (A.M.S.S.N.); araujofp15@gmail.com (F.P.A.); durcileneas@gmail.com (D.A.S.); josyosajima@ufpi.edu.br (J.A.O.)

2 Graduate Studies in Agronomy, Mato Grosso of Soulth Federal University, Chapadão do Sul 76560-000, Mato Grosso do Sul, Brazil; rfratke@gmail.com

3 Research Center on Biodiversity and Biotechnolog, Delta do Parnaíba Federal University, Parnaíba 64202-020, Piaui, Brazil

4 Veterinary Medicine Academic Unit, Campina Grande Federal University, Patos 58708-110, Paraíba, Brazil; leilson@ufpi.edu.br

* Correspondence: edsonfilho@ufpi.edu.br

Abstract: Agricultural production is influenced by the water content in the soil and availability of fertilizers. Thus, superabsorbent hydrogels, based on polyacrylamide, natural cashew tree gum (CG) and potassium hydrogen phosphate (PHP), as fertilizer and water releaser were developed. The structure, morphology, thermal stability and chemical composition of samples of polyacrylamide and cashew tree gum hydrogels with the presence of fertilizer (HCGP) and without fertilizer (HCG) were investigated, using X-ray diffractometry (XRD), Fourier Transformed Infrared Spectroscopy (FTIR), Scanning Electron Microscopy (SEM), Thermogravimetric Analysis (TGA/DTG) and Energy Dispersive Spectroscopy (EDS). Swelling/reswelling tests, textural analysis, effect of $\mathrm{pH}$, release of nutrients and kinetics were determined; the ecotoxicity of the hydrogels was investigated by the Artemia salina test. The results showed that PHP incorporation in the hydrogel favored the crosslinking of chains. This increased the thermal stability in HCGP but decreased the hardness and adhesion properties. The HCGP demonstrated good swelling capacity ( 15,000 times) and an excellent potential for reuse after fifty-five consecutive cycles. The swelling was favored in an alkaline $\mathrm{pH}$ due to the ionization of hydrophilic groups. The sustained release of phosphorus in HCGP was described by the Korsmeyer-Peppas model, and Fickian diffusion is the main fertilizer release mechanism. Finally, the hydrogels do not demonstrate toxicity, and HCGP has potential for application in agriculture.

Keywords: interpenetrating polymer network; controlled release fertilizer; agriculture

\section{Introduction}

Hydrogels are three-dimensional polymeric networks that have the ability to retain a large amount of the water and maintain their structural integrity [1-4]. These waterdilated networks are usually formed by polymers, which undergo physical or chemical crosslinking [5]. This high swelling capacity of hydrogels is due to the presence of hydrophilic groups, such as $-\mathrm{OH},-\mathrm{COOH}$, and $-\mathrm{SO}_{3} \mathrm{H}$, that are connected to the polymeric backbone [6-8]. The water absorbed by the material is stored in the empty spaces between the intercrossed polymeric chains that form the hydrogels. When the swelling capacity 
of hydrogels is very superior (above $100.0 \%$, for example), these materials are named superabsorbent hydrogels (SAHs).

In hydrogels, the three-dimensional structure is formed through covalent bonds (chemical hydrogels) or intermolecular interactions (physical hydrogels) [9]. It is also possible that these two types of interactions occur simultaneously [10]. For chemical hydrogels, the three-dimensional network is formed by polymerization and parallel crosslinking of monomers in the presence of a suitable crosslinking agent [11]. In the case of physical hydrogels, the intercrossing of the chains is formed only by the physical interactions between the macromolecules. In the case of physical hydrogels, the intercrossing of the chains is formed only by the physical interactions between the macromolecules which can occur in a variety of ways, including hydrophobic association, ionic interaction and hydrogen bonding $[1,10]$.

The term hydrogel was first described by Graham in 1864 in his studies of colloidal systems of silicic acid [12]. Over the years, these materials have received notoriety in different fields, including biomedical and pharmaceutical applications [13,14], tissue engineering $[15,16]$, water purification [17], and agriculture [18,19], among others. In agriculture applications, the use of hydrogels contributes to sustainable development and contemplates some of the objective and goal plans set out in the United Nations 2030 agenda. This is because hydrogels, especially SAHs, can store large volumes of water and minimize the waste that occurs with continuous irrigation. The maintenance of humidity in soil also favors a faster germination of the plant, improving the performance of agricultural cultivation [20]. In addition to water reserve systems, SAHs can also be used for the controlled release of fertilizers, which are substances that play an important role in soil fertility [21]. It is estimated that a significant percentage of fertilizers are not completely absorbed by the soil due to the high solubility of these substances in water [22]. For example, about $80.0 \%-90.0 \%$ of phosphorus cannot be absorbed by plants [23], also representing a great waste for agricultural systems. Thus, SAHs combined with fertilizer can improve plant nutrition, reduce water evaporation losses, minimize environmental pollution, and economic losses [24].

SAHs can be of the natural and synthetic type, depending on the polymers used in the synthesis process. Most commercial hydrogels are obtained from synthetic polymers, as they have excellent physical, chemical and mechanical properties [25]. The main polymers used in obtaining synthetic hydrogels are polycaprolactone, poly(vinyl pyrrolidone) (PVP), poly(lactic acid) (PLA), poly(ethylene glycol) (PEG), poly(vinyl alcohol) (PVA) and polyacrylamide (PAM) [26]. PAM is a conventional hydrophilic polymeric substance obtained through the polymerization of acrylamide, which takes place in three stages: initiation (generation of the active center), propagation (growth of the chain with transfer of active centers) and termination (interruption of polymerization due to the disappearance of the active center) [27].

The initiation of polymerization occurs through the use of thermally unstable initiators, which decompose into two active centers (radicals). Immediately, the active radical attacks the double bond of the monomer, transferring the active center and starting the polymerization. The polyacrylamide hydrogel is obtained in two simultaneous steps, which are polymerization and cross-linking. In the case under study, the redox initiator system used is composed of TEMED (tetramethylenediamide) and potassium persulfate (KPS) and the crosslinking agent is $N^{\prime}, N^{\prime}$-methylenebisacrylamide (MBA) [27].

PAM is a conventional hydrophilic polymeric substance that is used to obtain SAHs, mainly for application as soil conditioner [28,29]. Although PAM exhibits hydrogel formation capacity, chemical treatments, such as alkaline hydrolysis, have been suggested as a way to enhance the swelling of this synthetic polymer [29]. In general, SAH-based synthetic polymers have advantages, such as high swelling capacity and high durability [28]. However, synthetic polymers cannot be degraded in soil and this can represent a serious risk of environmental contamination [8].Thus, natural polymers have stood out as an option to 
reduce these disadvantages presented by synthetic polymers, and within natural polymers, polysaccharides have been shown to be an excellent option for the formation of SAHs.

Natural polysaccharides exhibit excellent biocompatibility, are biodegradable, are of a class distinct from natural polymers and have a large variety of structural characteristics [26]. Currently, they are being considered in the process of obtaining SAHs due to their economic and ecological viability [18]. In addition, these macromolecules improve the biodegradability, hydrophilicity and biocompatibility of hydrogels [30]. Some studies have simulated the use of different polysaccharides in obtaining hydrogels, such as cellulose [31], alginate [32], gelatin [29], and chitosan [33]; different gums are also related [34]. Natural gums are polysaccharides that can be obtained from exudates and seeds of terrestrial plants, algae and microorganism fermentation. However, plant gums are versatile and have a unique structure and functionality, being used in obtaining materials to ensure an eco-friendly synthesis route [35]. These polysaccharides have a heterogeneous composition and rheological properties that cannot be easily imitated by synthetic polymers [6]. In the presence of water, gums hydrate to form gels whose strength depends on the structure and concentration of the polysaccharide and factors such as $\mathrm{pH}$, temperature and ionic strength [36].

Some studies have explored obtaining SAHs based on tree gums, such as arabic [37], tragacanth [38], ghatti [39], and cashew tree gum (CG) [40]. However, some gums are imported from other continents and this causes an additional cost for the production of technologies. Thus, the use of typical natural polysaccharides in a given region can facilitate the production of new materials, in addition to being an ecologically friendly strategy. The CG is a natural exudate obtained of from the species Anacardium occidentale L. [41], which is found in the northeastern region of Brazil [42]. This gum has been used as a substitute for arabic gum, mainly in pharmaceutical applications [43]. Additionally, the extraction and purification of CG is an ecologically correct process [44], representing a sustainable alternative for obtaining new materials for agriculture. The CG consists of a mixture of saccharides instead of a long organic chain formed from chemically bonded units, such as galactose $(72-73 \%)$, glucose (11.0-14.0\%), arabinose (4.6-5.0\%), rhamnose (3.2-4.0\%) and glucuronic acid (4.7-6.3\%) [42]. Industrially, CG has applications in the food and pharmaceutical sectors, mainly as thickening, emulsifying and stabilizing agents [45]. Although some studies have reported the use of CG in obtaining SAHs [27,40,46], these materials were investigated only with respect to the structural, morphological and, obviously, water retention capacity.

In view of these considerations, SAHs play an important role for agricultural production. Therefore, in the present study, a new SAH based on CG and PAM was obtained for the controlled release of water and fertilizer. The swelling performance of SAHs has been investigated under different conditions, and the release of phosphorus as a nutrient was also investigated. These investigations should guide the application of this technology in agriculture.

\section{Results and Discussion}

\subsection{Structural and Morphological Characterization}

The X-ray diffraction patterns of the CG, PAM, PHP fertilizer, HCG and samples are shown in Figure 1a. According to XRD for CG, the broad diffused center at $2 \theta=19.5^{\circ}$ indicates a material with a low degree of structural organization, as reported by the literature [47]. The XRD pattern of the PAM showed a discrete, broad diffused center at $2 \theta=17.2$ that is associated with the amorphous nature of the polymeric matrix [48]. Others' peaks were observed at $2 \theta=44.1$ and $64.5^{\circ}$, suggesting the formation of a semicrystalline structure. Similar results were reported by Azzam et al. (2018), who synthesized PAM by the free radical polymerization method [49]. In a PHP diffractogram, a typical crystalline profile was identified, with peaks being observed at different values of $2 \theta$. All these peaks are in good agreement with standard COD 96-200-9611. For HCG and HCGP dry hydrogels, the diffractograms profile demonstrated as similar to the XRD of the PAM. However, the 
broad diffused associated the amorphous fraction of the PAM and CG polymers were not identified in the hydrogel samples. Peaks associated with PHP were not identified in the HCG and HCGP diffractograms.

The crystallinity index $(\mathrm{CrI})$ and variation of the crystallinity index $(\Delta \mathrm{CrI})$ were determined for the HCG, HCGP and PAM samples, as seen in Table 1. The HCG and HCGP hydrogels showed an increase in CrI values when compared to the value obtained for PAM. This suggests an increase in the crystallinity of HGC and HGCP samples, which may be associated with the interactions between the CG and PAM chains for the formation of hydrogels [50]. A $\Delta$ CrI value of $8.59 \%$ and $2.44 \%$ was observed for HCG and HCGP, respectively. According to the results, HCG demonstrated greater crystallinity compared to the hydrogel with fertilizer. The reduction in crystallinity may be a consequence of the increase in crosslinking network and a possible distortion in the polymeric network, due to the presence of PHP [50,51].
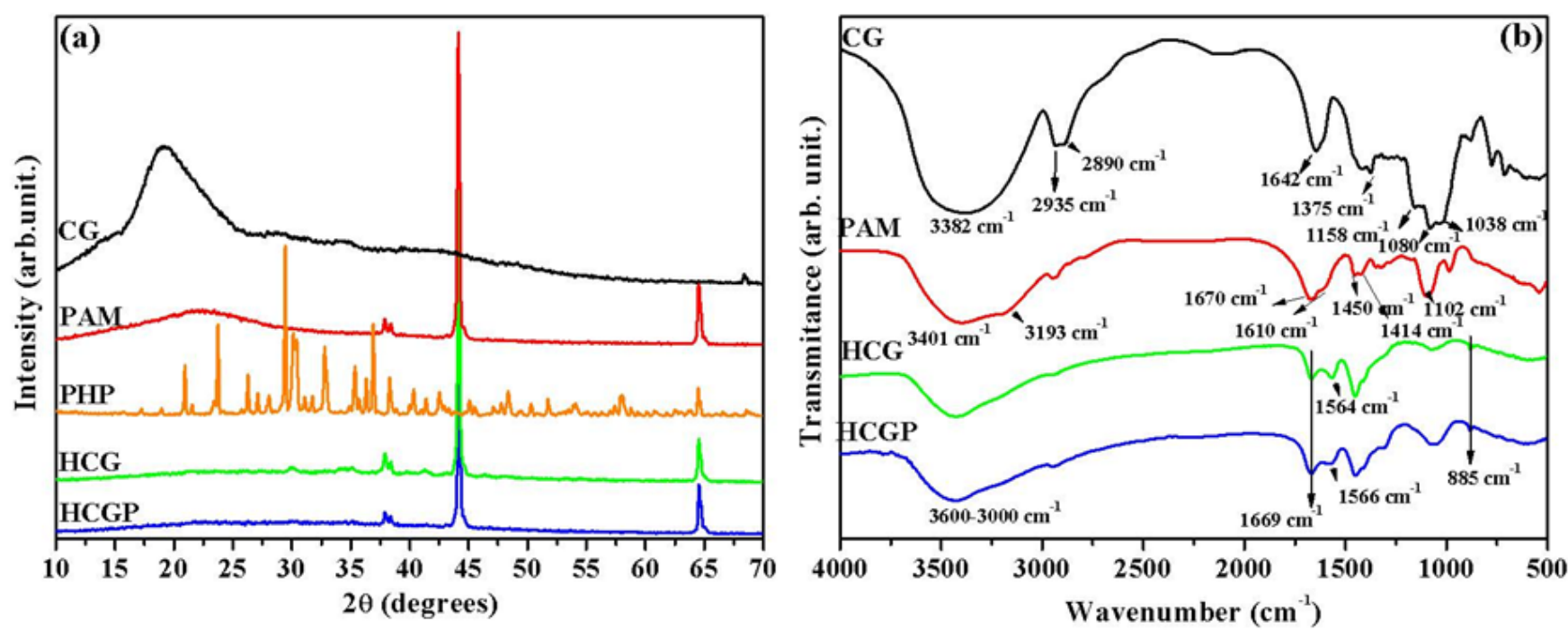

Figure 1. Structural characterization of hydrogel samples and isolated constituents by (a) XRD and (b) FTIR analysis.

Table 1. Values of CrI and $\Delta \mathrm{CrI}$ determined for HCG and HCGP hydrogels.

\begin{tabular}{ccc}
\hline Sample & CrI & $(\Delta \mathbf{C r I}) \%$ \\
\hline PAM & 77.98 & - \\
HGC & 84.69 & 8.59 \\
HGCP & 79.89 & 2.44 \\
\hline
\end{tabular}

The functional groups present in the materials were investigated by FTIR analysis, and these results are shown in Figure 1b. The FTIR spectrum of CG revealed the presence of bands at $3382 \mathrm{~cm}^{-1}$ that are associated with stretching the $\mathrm{O}-\mathrm{H}$ bond in hydroxyl groups [52]. The bands at 2935 and $2890 \mathrm{~cm}^{-1}$ are referent to $\mathrm{C}-\mathrm{H}$ stretching (asymmetric and symmetric, respectively), while the bands present at 1642 and $1375 \mathrm{~cm}^{-1}$ are associated with the deformation of the $\mathrm{O}-\mathrm{H}$ bond and flexion of the $\mathrm{C}-\mathrm{H}$ bond, respectively [47]. Other bands evidenced at 1158,1080 and $1038 \mathrm{~cm}^{-1}$ are due to $\mathrm{C}-\mathrm{O}-\mathrm{C}$ glycosidic bonds and $\mathrm{O}-\mathrm{H}$ bending from alcohols [27,47]. The typical bands of PAM were observed at 3401 and $3193 \mathrm{~cm}^{-1}$, corresponding to axial deformation vibrations in the $\mathrm{N}-\mathrm{H}$ bond $[53,54]$. The two bands at 1670 and $1610 \mathrm{~cm}^{-1}$ are associated with the $\mathrm{C}=\mathrm{O}$ stretching vibration in amide, and $\mathrm{N}-\mathrm{H}$ stretching vibration in amide, respectively $[27,48]$. Others' bands, identified at 1450, 1414 , and $1102 \mathrm{~cm}^{-1}$, were attributed to- $\mathrm{CH}_{2}$ scissoring, $\mathrm{CN}$ and $\mathrm{N}-\mathrm{H}$ stretching vibrations [55].

The FTIR spectra of the prepared HCG and HCGP dry samples showed bands characteristic of the functional groups of CG and PAM polymers. The band observed in the range between 3600 and $3000 \mathrm{~cm}^{-1}$ may be attributed to the overlap of the $\mathrm{N}-\mathrm{H}$ and $\mathrm{O}-\mathrm{H}$ 
stretching vibration [56,57]; the overlapping of the bands may have occurred due to the presence of physically adsorbed water, since this presence greatly expands the band in this region, while the band at $1669 \mathrm{~cm}^{-1}$ corresponds to the $\mathrm{C}=\mathrm{O}$ stretching present in the PAM structure. The decrease in the intensity of this band was noted for HCG and HCGP; this result is probably associated with the hydrolysis reactions, in which the amide groups $\left(\mathrm{CONH}_{2}\right)$ were converted to carboxylate groups (COONa) [58]. In addition, the band associated with $\mathrm{N}-\mathrm{H}$ stretching vibration in the amide group was shifted to 1564 and $1566 \mathrm{~cm}^{-1}$ in the HCG and HCGP spectra, indicating the occurrence of crosslinking reactions [40]. This band shift may be due to interactions between the polysaccharide and PAM chains. It is well known that the formation of hydrogen bonds reduces the strength constants of chemical bonds, shifting the vibrational frequency to lower wavenumbers [59]. The band displayed at $885 \mathrm{~cm}^{-1}$ in the HCG and HCGP spectrum corresponds to out-ofplane $\mathrm{C}-\mathrm{H}$ bending vibrations, which can be associated with the polysaccharide structure. The bands associated with PHP fertilizer were not identified in the HCGP spectrum, due to the overlap between typical bands of vibrations in the phosphate group and the structure of the polymers. As reported in the literature, the bands associated with the stretching vibration in $\mathrm{P}=\mathrm{O}$ and $\mathrm{P}-\mathrm{O}$ are expected at 1109 and $819 \mathrm{~cm}^{-1}$ [24]. A summary of the main bands and their assignments is described in Table 2.

Table 2. FTIR bands and their assignments for CG, PAM, HCG and HCGP.

\begin{tabular}{|c|c|c|}
\hline Sample & Wave Number $\left(\mathrm{cm}^{-1}\right)$ & Functional Group/Chemical Bond \\
\hline \multirow{4}{*}{ HCG } & 3382 & Stretching $\mathrm{O}-\mathrm{H}$ bond in hydroxyl groups \\
\hline & 2935 and 2890 & C-H stretching \\
\hline & 1642 and 1375 & Deformation $\mathrm{O}-\mathrm{H}$ bond and flexion $\mathrm{C}-\mathrm{H}$ bond \\
\hline & 1158,1080 and 1038 & $\mathrm{C}-\mathrm{O}-\mathrm{C}$ glycosidic bonds and $\mathrm{O}-\mathrm{H}$ bending from alcohols \\
\hline \multirow{3}{*}{ PAM } & 3401 and 3193 & Axial deformation vibrations in $\mathrm{N}-\mathrm{H}$ bond \\
\hline & 1670 and 1610 & $\mathrm{C}=\mathrm{O}$ stretching vibration in amide and $\mathrm{N}-\mathrm{H}$ stretching vibration in amide \\
\hline & 1450,1414 , and 1102 & $-\mathrm{CH}_{2}$ scissoring, $\mathrm{CN}$ and $\mathrm{N}-\mathrm{H}$ stretching vibrations \\
\hline \multirow{4}{*}{ HCG and HCGP } & $3600-3000$ & Overlap of the $\mathrm{N}-\mathrm{H}$ and $\mathrm{O}-\mathrm{H}$ stretching vibration \\
\hline & 1669 & $\mathrm{C}=\mathrm{O}$ stretching \\
\hline & 1564 and 1566 & $\mathrm{~N}-\mathrm{H}$ stretching vibration in amide group \\
\hline & 885 & Out-of-plane C-H bending vibrations \\
\hline
\end{tabular}

The thermal behaviors of CG, HCGP and HCGdry samples are shown in Figure 2. Based on the TGA and DTG curves for the CG polysaccharide, the thermal event observed at $56^{\circ} \mathrm{C}(\sim 13.9 \%$ mass loss $)$ is due to water release [47]. Other thermal events that occurred at 254 and $305^{\circ} \mathrm{C}(69.5 \%$ mass loss) are associated with the thermal degradation of the polysaccharide structure [60]. For the HCG sample, four thermal events were observed. The three initial events occurred up to $275^{\circ} \mathrm{C}$ (total mass loss at $\sim 6.7 \%$ ) and are associated with the release of surface water. The last stage of thermal decomposition observed at $354{ }^{\circ} \mathrm{C}$ (63.5\% mass loss) may be related with thermal degradation of the material.

According to the TGA and DTG curves of the HCGP, the thermal decomposition of this sample occurred in six stages of mass loss. The first two stages below $100{ }^{\circ} \mathrm{C}$ (mass loss at $27.4 \%$ ) may be associated with the release of water or other volatile compounds adsorbed on the material's surface. The events observed in the range between 200 and $300{ }^{\circ} \mathrm{C}$ (with mass loss at $8.7 \%$ ) and in the region above $350{ }^{\circ} \mathrm{C}$ (mass loss at $20.2 \%$ ) are related to the thermal decomposition of the material. Both for HCG and HCGP samples, the thermal degradation behavior was consistent with the data reported in the literature for polymer based on PAM [61].

Comparing the TGA curves of CG, HCG and HCGP samples, it was observed that mass residue increases in the following order: CG $<$ HCG $<$ HCGP. This result indicates that HCGP had improved thermal stability [29]. The higher thermal stability of the HCGP compared to HCG may be attributed to the formation of crosslinks in the hydrogel matrix [25]. It can be explained that the presence of PHP promoted an increase in the crosslinking 
reactions during hydrogel formation. In addition, the presence of PHP, which is an inorganic compound that does not degrade, may also have contributed to improvements in the thermal stability of HCGP.
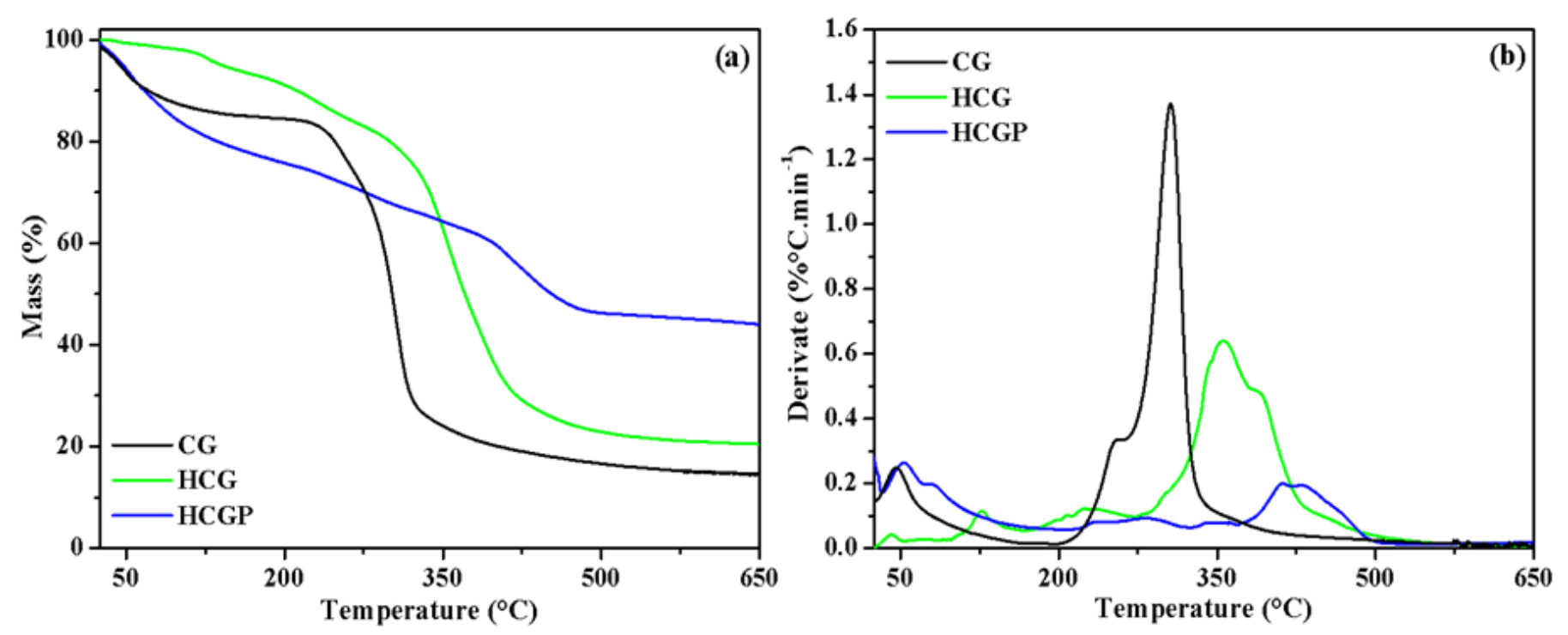

Figure 2. Thermal analysis of CG, HCG and HCGP sample investigated by (a) TGA and (b) DTG curves.

The morphology of the HCG and HCGP was analyzed by the SEM technique in different magnifications, and the results are presented in Figure 3. All the samples were freeze-dried before the SEM morphological analyses. According to these results, HCG (Figure $3 \mathrm{a}, \mathrm{b}$ ) demonstrated surface roughness, being observed in the presence of some agglomerates. Although HCG has demonstrated a more compact surface, this material seems to demonstrate small spaces, probably pores, which should favor the entry of liquids into the hydrogel [8]. Based on the SEM images obtained for the HCGP, it is evident that the addition of PHP completely changed the morphology on the surface material (Figure 3c,d). In this case, a peculiar architecture, formed by fine crystals that grow in parallel, was observed in HCGP. These elongated structures are evenly distributed on the HCGP surface, forming pores that should allow the swelling of the hydrogel [62].

The EDS mapping was performed to analyze the chemical composition of the sample's surface, and the results are shown in Figure 3e,f. The presence of carbon (C) and oxygen (O) peaks were identified in both the HCG and HCGP spectra and are associated with the organic composition of the materials. In particular, HCG demonstrated a peak related to the sodium element $(\mathrm{Na})$, due to formation of sodium carboxylate groups (COONa) during the hydrolysis process [29]. Peaks associated with potassium (K) and phosphorus (P) atoms were identified in the HCGP spectra and confirm the presence of the PHP fertilizer in this sample.

Hydrogels are materials that have a high affinity for water. The water retention capacity of hydrogels is very important to make their application in agriculture feasible. Thus, the swelling of the materials was investigated and the results are shown in Figure 4. In general, the samples showed rapidly swelled in $60 \mathrm{~min}$, and an equilibrium condition occurred in $120 \mathrm{~min}$. According to Figure 4a, it can be seen that the swelling capacity of the HCG hydrogel was greater than that of the HCGP hydrogel. For example, while HCG swelled 24,000 times in relation to the initial mass, HCGP swelled 15,000 times. It is well reported that the expansion of the hydrogel decreases according to the increase in the crosslink density of the hydrogels [63]. The increase in crosslinking points, causes greater proximity to the three-dimensional networks and, consequently, limits the entry of water into the hydrogel $[24,25]$. In this way, it is assumed that the addition of fertilizer may have increased the crosslink density in HCGP, resulting in a decreased swelling capacity for this sample. These results corroborated with the thermal stability data presented in Section 2.1. 
An illustration of the swelling capacity of HCG and HCGP is also shown in Figure 4b,c and prove the efficiency of superabsorbent for both hydrogels. Table 3 summarizes the swelling capacity of other hydrogels based on polysaccharides, as presented in the literature.
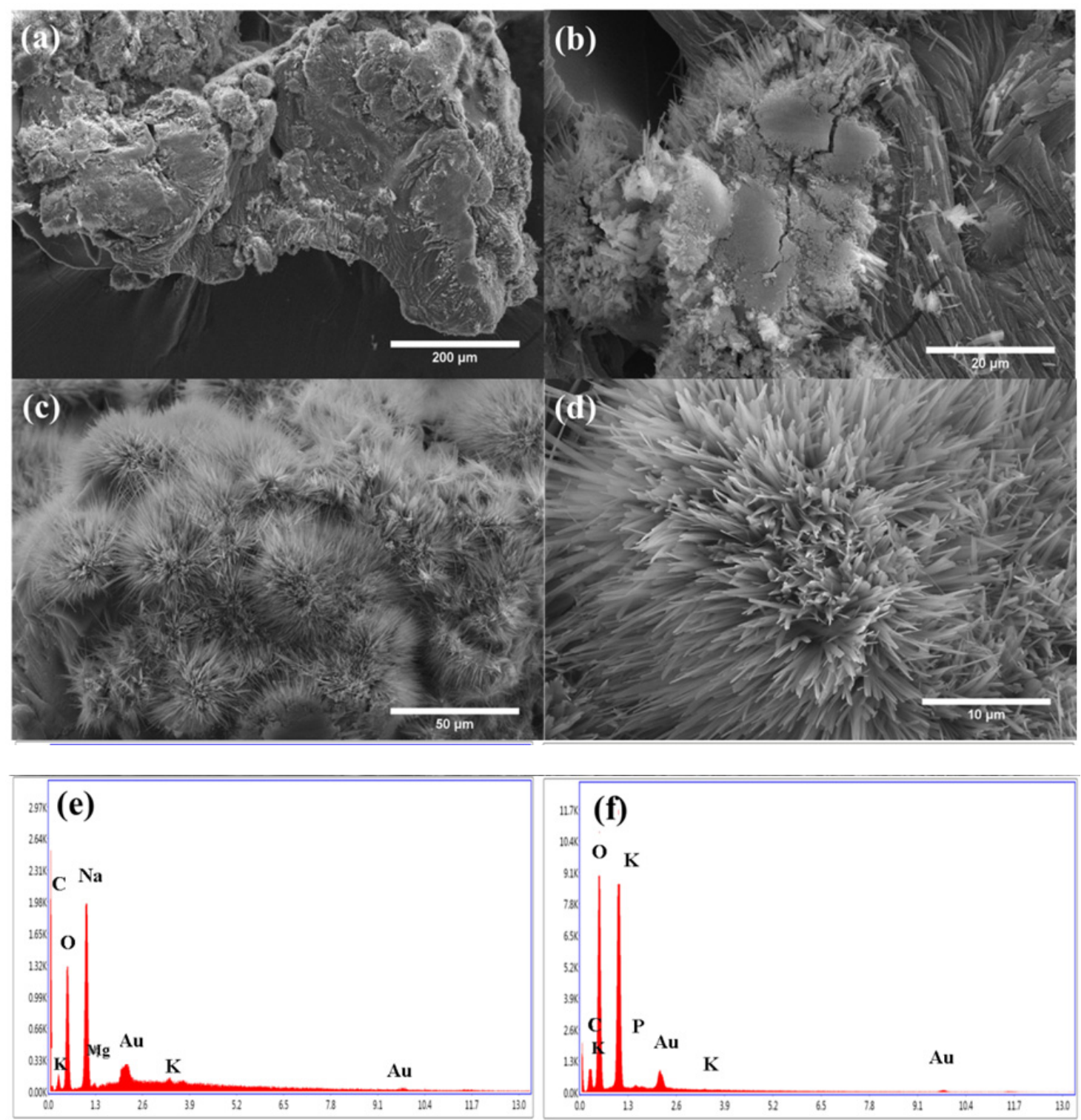

Figure 3. SEM images in different magnifications for samples (a,b) HCG, (c,d) HCGP and semi-quantitative analyses by EDS for the (e) HCGand (f) HCGP samples.

In order to examine the potential of HCG and HCGP as soil conditioners, reswelling tests were performed. These results are expressed in relation to the swelling capacity in consecutive cycles and time of water release by hydrogels, as shown in Figure 5. The reswelling capacity of hydrogels after consecutive cycles is an important characteristic to attest the viability of this material in agricultural applications [68]. As observed in Figure 5a, the HCG and HCGP hydrogels demonstrated a constant reswelling capacity during reuse tests. The results suggest that the continuous drying process do not alter the structure of the hydrogels. It is well known that the continuous drying of hydrogels promotes strong interactions of the type of hydrogen bonds between carboxylate and hydroxyl groups present in the polymer chain [69]. Thus, a decrease in network expansion can be expected. 


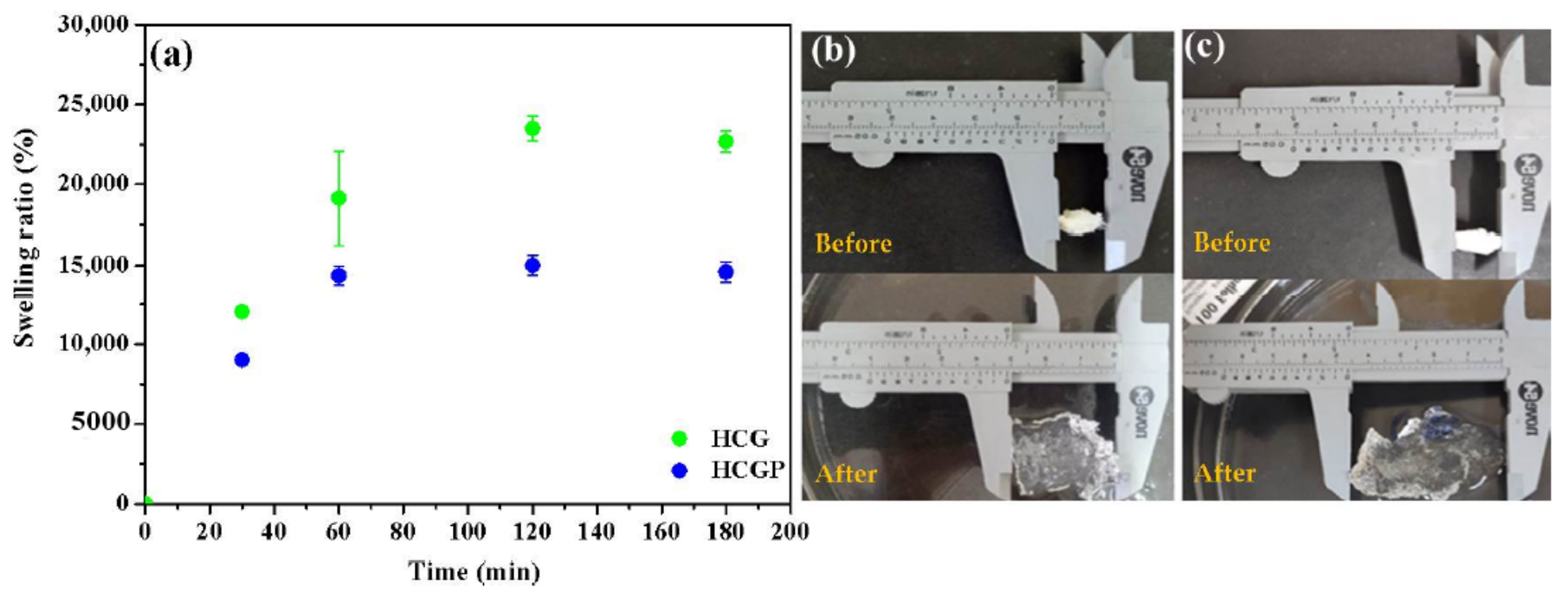

Figure 4. (a) Swelling degree as a function of time for the hydrogels samples and physical changes in superabsorbent; (b) HCG and (c) HCGP before and after the swelling test.

Table 3. Swelling capacity of hydrogels based on other polysaccharides.

\begin{tabular}{ccc}
\hline Hydrogel Type & Swelling Capacity (g/g) & Reference \\
\hline Tamarind kernel gum & 648 & {$[8]$} \\
Guar gum & 625 & {$[58]$} \\
Agar & 14 & {$[62]$} \\
Lignin & 280 & {$[64]$} \\
Galactomannan & 115 & {$[65]$} \\
Acrylic acid & 5066 & {$[66]$} \\
Agarose & 15 & {$[67]$} \\
Starch & 921.8 & {$[68]$} \\
Cashew tree gum & 240 & This work \\
Cashew tree gum with fertilizer & 150 & This work \\
\hline
\end{tabular}
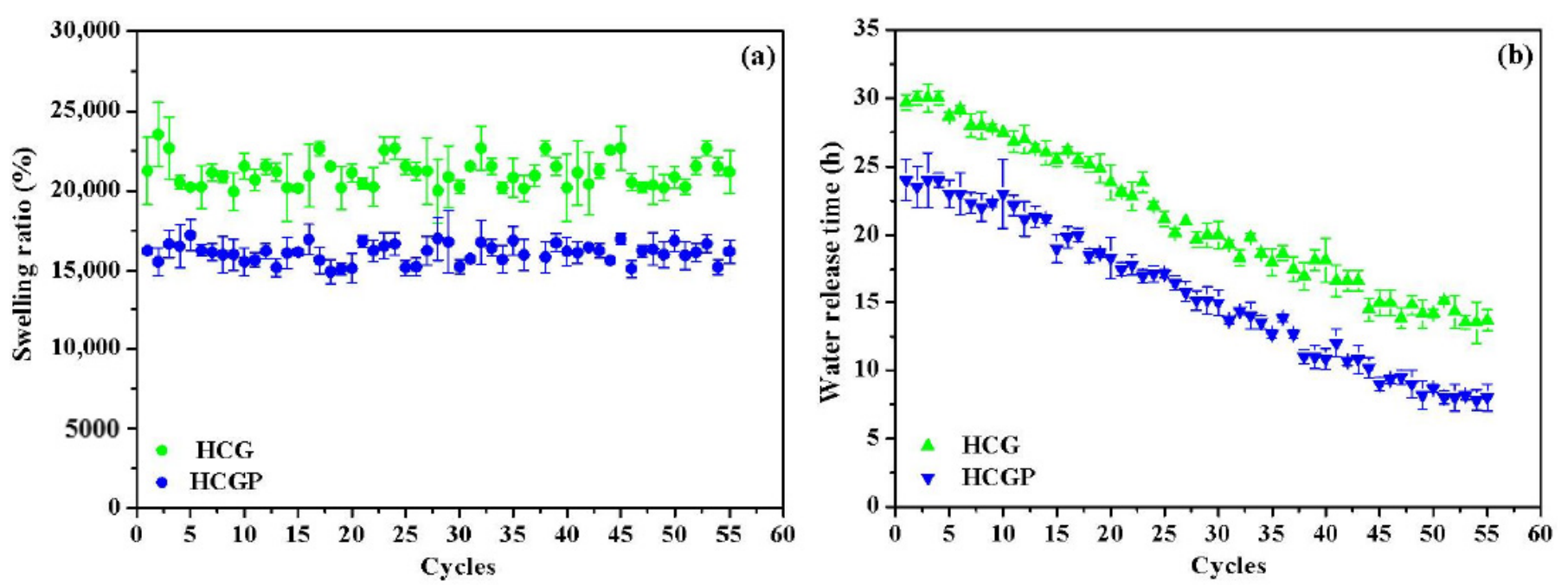

Figure 5. Evaluation of the (a) reswelling capacity and (b) water release time by HCG and HCGP hydrogels.

Based on the results of the water release time by hydrogels shown in Figure $5 b$, a decrease in water elimination time for both hydrogels was demonstrated. For HCG hydrogel, initially, the release of water in the first cycle occurred in $30 \mathrm{~h}$. In the last reuse cycle, the time required to remove water from the structure was $13.5 \mathrm{~h}$. This represents a decrease of $55.0 \%$ in the water release time. For the HCGP hydrogel, the water release time 
in the first cycle was $24 \mathrm{~h}$. At the end of the fifty-fifth cycle, the water release time was $8 \mathrm{~h}$, reducing $67.0 \%$ of the time required to dry completely. This behavior can be explained based on the morphology presented by these materials. As demonstrated in the SEM images in Section 2.1, the HCGP showed much finer crystals than the HCG sample. The low thickness of the crystal in HCGP promotes a quick diffusion of water in the structure, facilitating the water release [63]. It is probable that the repeated drying process collapsed the walls of both materials, resulting in a decrease in drying time.

The swelling property of the hydrogel is strongly dependent on external ambient parameters, such as temperature, $\mathrm{pH}$ and ionic concentration [70,71]. In particular, the study on the effect of $\mathrm{pH}$ is considered important for application in agriculture, because the soils may have an acidic, neutral or alkaline character. The effect of $\mathrm{pH}$ on the swelling behaviors of HCG and HCGP hydrogel was investigated in various $\mathrm{pH}$ solutions as displayed in Figure 6. The swelling property of the materials was drastically affected when the $\mathrm{pH}$ of the medium was modified. Comparing the swelling capacity at different $\mathrm{pH}$ values, it was observed that the swelling ratio in both hydrogels increases with increasing the $\mathrm{pH}$ of the solution.

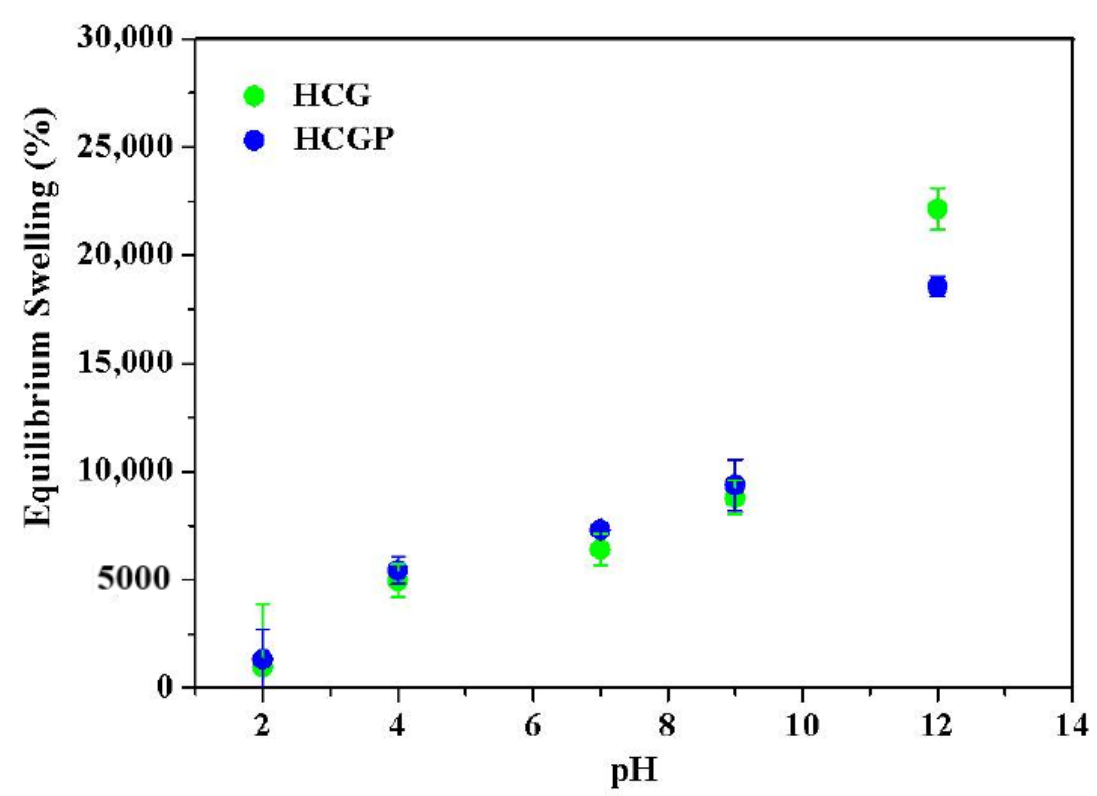

Figure 6. Investigation of the pH-dependent equilibrium swelling ratio of the HCG and HCGP hydrogels.

In an acidic $\mathrm{pH}$ environment, the swelling capacity was drastically reduced, especially while $\mathrm{pH} 2$ was used for swelling of hydrogels. In this condition, the carboxylate anions $\left(\mathrm{COO}^{-}\right)$are protonated and this minimize the repulsive anion-anion forces [8,32] Consequently, the polymeric material becomes more hydrophobic, making swelling more difficult. In addition, hydrogen bonds are favored at an acidic $\mathrm{pH}$ and this implies an increase in the degree of physical crosslinking of the chains [25]. Hydrogen bonding type interactions restrict the movement or relaxation of the chains present in the material and form a compact hydrogel network [72]. As discussed, a large number of crosslinking points reduces the physical space for water retention. When the swelling $\mathrm{pH}$ of the hydrogels was increased to values above 7.0, a high swelling capacity for the hydrogels was observed. This may have been due to the ionization of hydrophilic groups present in HCG and HCGP in an alkaline $\mathrm{pH}$. The formation of additional physical crosslinking is disadvantaged in situations where the $\mathrm{pH}$ is alkaline. In this case, the ionization promotes an electrostatic repulsion between the chains, facilitating the expansion of the hydrogel [25].Consequently, the hydrogels' swelling capacity was higher in an alkaline medium. The better performance was achieved at pH 12 for all the samples. 
Figure 7 displays the release behaviour of phosphorus in HCGP hydrogel. Initially, a rapid increase in the concentration of fertilizer released was observed. This may be associated with the high solubility fertilizer adsorbed on the surface. After four hours, a sustained release was achieved. In the equilibrium condition, the phosphorus concentration found was $2.5 \mathrm{mg} \mathrm{L}^{-1}$. BaKi et al. (2018) observed a similar behavior for SHAs based on polyacrylamide grafted with sodium alginate and biochar [73]. The slow release of fertilizer is important to ensure better nutrient absorption and minimize nutrient loss [74]. Thus, HCGP demonstrated a potential for controlled nutrient delivery systems.

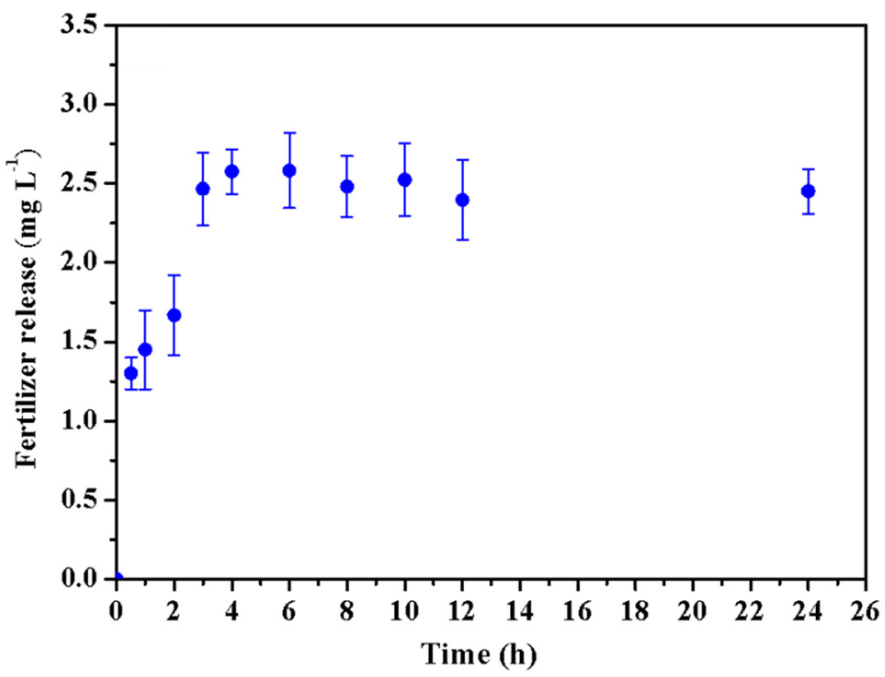

Figure 7. Phosphorus release from the HCGP hydrogel.

The physical mechanism of fertilizer release by the HCGP hydrogel was determined by comparing the release data with mathematical models of zero order, first order, the Higuchi model and the Korsmeyer-Peppas model. These results are presented in Figure 8. The experimental data did not show a good fit for the zero order and first order models, as indicated by their low regression values $\left(R^{2}=0.2102\right.$ and 0.1952 , respectively). It can be observed that the release of fertilizer has higher values of linear regression for the Higuchi and Korsmeyer-Peppas models $\left(R^{2}=0.5323\right.$ and 0.6884 , respectively). However, comparing these values with each other, the data have a better fit for the KorsmeyerPeppas model. To understand the PHP release mechanism, the value of $\mathrm{n}$ was determined according to Equation (7), presented in Section 3.6. The value of $\mathrm{n}$ was found to be $\sim 0.2$. It is well reported that for $\mathrm{n}<0.45$, the Fickian diffusion mechanism is predominant $[75,76]$, indicating that the diffusion process is the main mechanism involved in transporting PHP molecules through polymeric hydrogel networks [76].

The texture properties are influenced by the composition of hydrogels. In this study, the effect of adding fertilizer on properties such as hardness, deformation, adhesion strength and adhesiveness was investigated, as shown in Table 4. The HGC hydrogel showed higher values for all parameters investigated in the texture analysis. The hardness is crucial to evaluate the durability of a material and, consequently, to ensure better performance during the application [77]. The hardness value of the HCG was 6.2 times superior compared to the HCGP sample. The HGC hydrogel also exhibited superior adhesion strength and adhesiveness values, as seen in Table 4. As noted in the swelling tests, HCG demonstrated a greater ability to retain water than HCGP. Studies are associated with adhesion properties of the increase in crosslink density. More specifically, the existence of hydroxyl groups on the surface that are not crosslinked favors interaction with the substrate and improves the adhesion of the material [78]. In addition, the greater roughness on the HCG surface observed in SEM analysis may also have contributed to improving the sample's adhesion properties. 

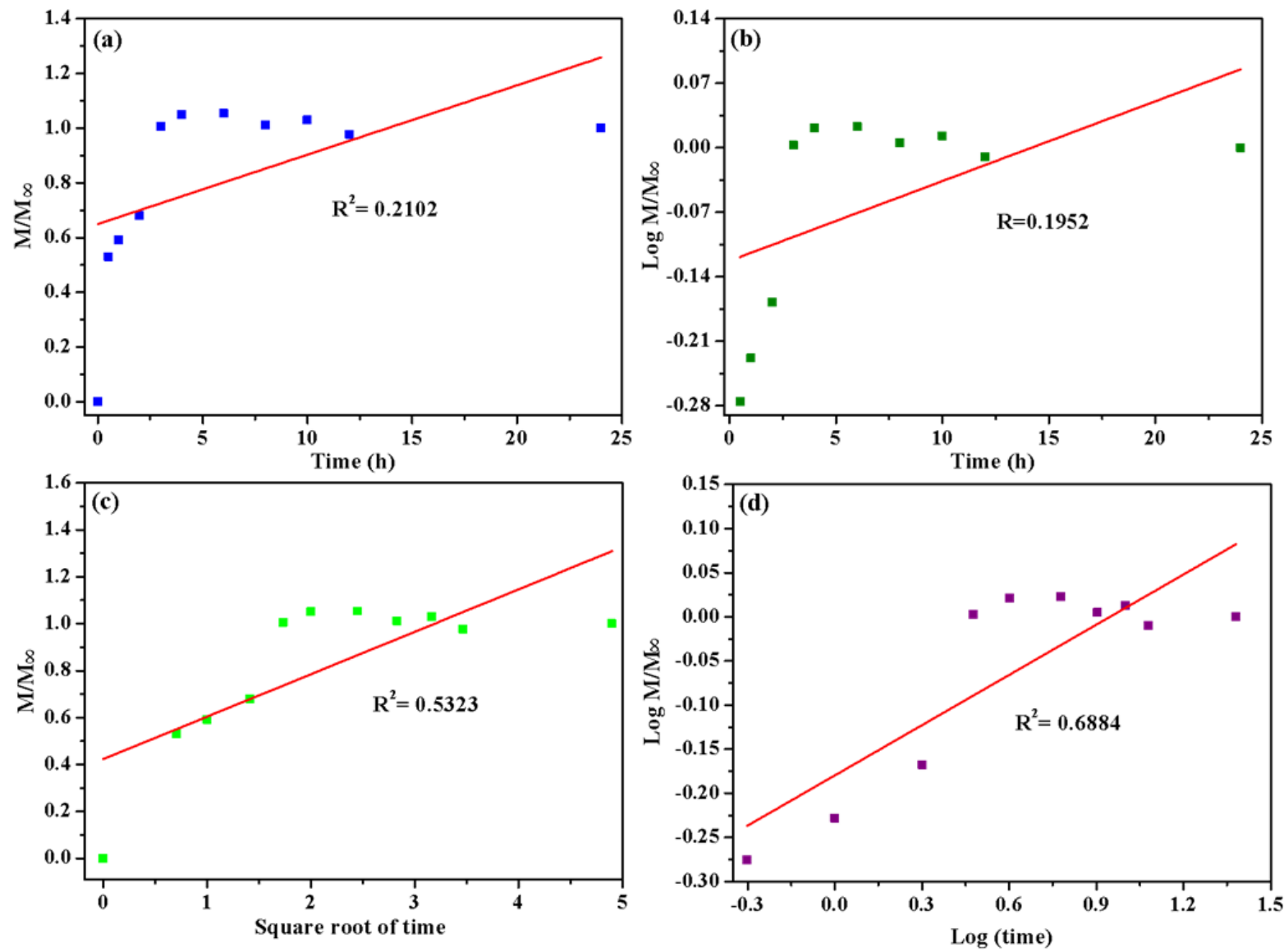

Figure 8. Fertilizer release kinetics according to mathematical models: (a) zero order, (b) first order, (c) Higuchi and (d) Korsmeyer-Peppas.

Table 4. Textural analysis for HCG and HCGP hydrogels.

\begin{tabular}{cccc}
\hline Sample & Hardness $(\mathbf{g})$ & Adhesion Strength $(\mathrm{g})$ & Adhesiveness $(\mathbf{m})$ \\
\hline HCG & 1345.0 & 45.0 & 9.4 \\
HCGP & 215.0 & 25.0 & 1.4 \\
\hline
\end{tabular}

\subsection{Grafting Mechanism}

The copolymerization mechanism by grafting the PAM with polysaccharides using redox initiators starts when it is decomposed by heat, generating the sulfate anion radical, which can react with water and generate hydroxyl radicals. Theses radicals are named primary radical $\left(\mathrm{R}^{\bullet}\right)$, which behaves as an active center to initiate the polymerization of PAM [27,79-81] as shown in Figure 9. The propagation step follows the reaction of cashew tree gum (CG-OX) with the radicals and monomers. Finally, the termination step occurs when the macroradicals react by themselves, forming the copolymer.

\subsection{Ecotoxicity}

To ensure that PAM and CG polysaccharide grafting, as well as the addition of fertilizer, do not promote the toxicity of the final material, ecotoxicity tests in Artermia salina were performed with HCG and HCGP samples. These microcrustaceans occur naturally in aquatic environments, and are sensitive to contaminants even at low concentrations [82]. The results collected during ecotoxicity test are illustrated in Figure 10. 
Initiation

$$
\begin{aligned}
& \mathrm{S}_{2} \mathrm{O}_{8}{ }^{2-} \rightarrow 2 \mathrm{SO}_{4}{ }^{-} \\
& 2 \mathrm{SO}_{4}{ }^{-}+\mathrm{H}_{2} \mathrm{O} \rightarrow \mathrm{SO}_{4}{ }^{-}+\mathrm{OH}^{\cdot}+\mathrm{H}^{+}
\end{aligned}
$$

Primary radicals formation $\mathrm{R}^{\bullet}=\mathrm{SO}_{4}{ }^{\bullet}$ or $\mathrm{OH}^{*}$

Propagation

$$
\begin{aligned}
& \mathrm{R}^{\bullet}+\mathrm{AM} \rightarrow \mathrm{R}-\mathrm{AM} \bullet \\
& \mathrm{R}-\mathrm{AM}^{\bullet}+\mathrm{n} A M \rightarrow \mathrm{R}^{-\mathrm{AM}^{\bullet}}{ }_{\mathrm{n}+1} \\
& \mathrm{CG}-\mathrm{OX}+\mathrm{R}^{\bullet} \rightarrow \mathrm{CG}-\mathrm{O}^{\bullet}+\mathrm{RX} \\
& \text { CG-O + AM } \rightarrow \text { CG-O-AM }{ }^{\bullet} \\
& \mathrm{CG}-\mathrm{O}^{\bullet}+\mathrm{nAM} \rightarrow \mathrm{CG}^{-O}-\mathrm{AM}^{\bullet}{ }_{\mathrm{n}+1}
\end{aligned}
$$

Termination

$$
\begin{aligned}
& \text { CG-O-AM }+ \text { R-AM } \rightarrow \text { CG-O-AM-CO-AM + R-H } \\
& \text { CG-O-AM• } \rightarrow \text { CG-O-AM-CO-AM-R-CG }
\end{aligned}
$$

Figure 9. Scheme of copolymerization reaction of the cashew tree range with polyacrylamide, where $\mathrm{CG}=$ cashew tree gum; $\mathrm{R}=$ Primary radicals $\left(\mathrm{SO}_{4}{ }^{\bullet}\right.$ or $\left.\mathrm{OH}^{\bullet}\right), \mathrm{AM}=$ Acrylamide .
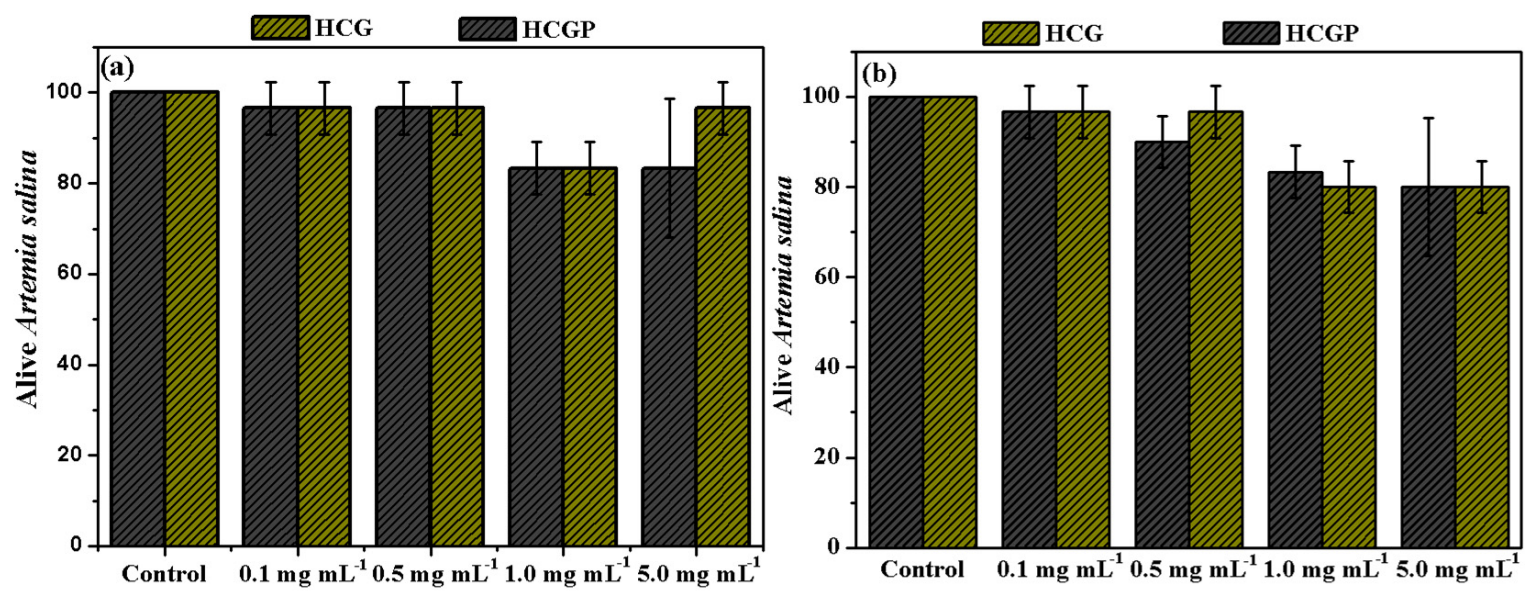

Figure 10. Determination of ecotoxicity in Artemia salina for HCG and HCGP hydrogels after (a) 24 and (b) 48 h.

Based on the amount of live nauplii in ecotoxicity tests, the hydrogels demonstrated no toxicity. After $24 \mathrm{~h}$, the amount of the alive nauplii was greater than $80.0 \%$ in all concentrations studied. These results are similar to those observed for the control group, where the nauplii were grown in an adequate medium, that is, in saline solution. After $48 \mathrm{~h}$, the amount the alive nauplii remained above $50.0 \%$, confirming the non-toxicity of all the samples. As described by the literature, the CG polysaccharide and PAM do not exhibit significant toxicity $[29,83]$. Acrylamide is a water-soluble substance and has high toxicity [84]. As evidenced in the results of Figure 9, a survival rate of the nauplii above $80.0 \%$ was observed, even after $48 \mathrm{~h}$ of contact with extracts of the samples of hydrogels [85-89]. This result also suggests that acrylamide residues do not exist in the samples. Finally, the ecotoxicity results indicate that HCG and HCGP hydrogels do not present risks for use in agriculture. 


\section{Materials and Methods}

\subsection{Materials}

The following reagents were used to obtain the hydrogels: Acrylamide, $-98.0 \%$ (Aldrich, St. Louis, MO, USA); $N, N, N^{\prime}, N^{\prime}$-tetramethylenediamine-TEMED, $-99.0 \%$ (Aldrich), as reaction accelerator; potassium persulfate- $\mathrm{K}_{2} \mathrm{~S}_{2} \mathrm{O}_{8}-\mathrm{KPS}-99.0 \%$ (Aldrich) as initiator; crosslinker $N, N^{\prime}$-methylenebisacrylamide-MBA -99.0\% (Aldrich); sodium hydroxide$\mathrm{NaOH}-97.0 \%$ (Aldrich); potassium bicarbonate- $\mathrm{KHCO}_{3}-99.5 \%$ (Aldrich); potassium hydrogen phosphate- $\mathrm{K}_{2} \mathrm{HPO}_{4}-99.0 \%$ (Exodus);methanol- $\mathrm{CH}_{3} \mathrm{OH}-99.8 \%$ (Dynamic); ascorbic acid, 99.0\% (Aldrich); acetone, 99.5\% (Dynamic); ethanol, 99.8\% (Dynamic); cashew gum isolated and deionized water were used without previous purification.

\subsection{Cashew Tree Gum Production}

For the isolation and purification of the CG, the procedure previously reported in the literature was used. Initially, the exudates were collected from the tree (Anacardium occidentale L.) located at the Federal University of Piauí-UFPI (SISGEN: ABD61DA). Then, the impurities were removed manually, and lighter and lump-free nodules and impurities were selected. The exudate was dissolved in distilled water (10.0 $\mathrm{g}$ in $100.0 \mathrm{~mL}$ of water) under mechanical stirring $(2000 \mathrm{rpm})$ for $24 \mathrm{~h}$. The solution obtained was filtered under vacuum and then the $\mathrm{pH}$ was adjusted $(\mathrm{pH} 7.0)$ with the addition of $\mathrm{NaOH}$ solution $\left(0.5 \mathrm{~mol} \mathrm{~L}^{-1}\right)$. The GC was obtained by precipitation of the solution with anhydrous ethanol in a volume ratio of 3:1 $(v / v)$. The precipitate obtained was centrifuged and washed with acetone. Finally, the gum was kiln dried at $50{ }^{\circ} \mathrm{C}$ for $24 \mathrm{~h}$ [90]

\subsection{Hydrogels Synthesis}

To obtain hydrogels with fertilizer (HCGP) and without fertilizer (HCG), $2.0 \mathrm{~g}$ of CG were dissolved in $30.0 \mathrm{~mL}$ of water, under agitation and bubbling with nitrogen gas to reduce the effect of oxygen in the atmosphere on the reaction of polymerization. Then, $0.024 \mathrm{~g}$ of $\mathrm{K}_{2} \mathrm{HPO}_{4}$ and $2.10 \mathrm{~g}$ of acrylamide monomer were added to the gum solution. After homogenization, $0.016 \mathrm{~g}$ of the KPS primer, $0.024 \mathrm{~g}$ of the MBA crosslinker and $100.0 \mathrm{mg}$ of $\mathrm{KHCO} 3$ were added to the sequence. After $5 \mathrm{~min}$ of stirring and bubbling with nitrogen, $100.0 \mu \mathrm{L}$ of the TEMED accelerator was added to the solution. The system was closed and kept under nitrogen and stirred until the gel point was reached. The obtained gel was washed with a $30.0 \%(v / v)$ aqueous methanol solution to remove residual acrylamide. The material was lyophilized for four days to obtain a dry and constant mass [27].

After drying, the material was subjected to an alkaline hydrolysis reaction for the conversion of its amide groups into carboxylates, increasing the number of hydroxyls, thus making the material more hydrophilic. Thus, $1.0 \mathrm{~g}$ of the dry hydrogel was mixed with $40.0 \mathrm{~mL}$ of $\mathrm{NaOH}$ solution $\left(0.5 \mathrm{~mol} \mathrm{~L}^{-1}\right)$. After finishing this reaction, the materials were washed with deionized water and lyophilized [29].

The fertilizer-free hydrogel (HCG) was prepared similarly to the HCGP hydrogel, but $\mathrm{K}_{2} \mathrm{HPO}_{4}$ was not added during the synthesis process. In addition, PAM was also synthesized in this study.

\subsection{Characterizations}

The dry HCG and HCGP samples were characterized by the X-ray diffraction (XRD) technique (Shimadzu (LABX-XDR 600, Shimadzu, Kyoto, Japan) with Cu-K $\alpha(\lambda=1.5406 \AA)$ ), using a scan rate of $5^{\circ} \mathrm{min}^{-1}$. From the XRD data, the relative crystallinity was determined using the crystallinity index $(\mathrm{CrI})$ that was calculated by Equation (1):

$$
\operatorname{CrI}(\%)=\frac{I_{F}-I_{S}}{I_{F}} \times 100
$$


where $\mathrm{I}_{\mathrm{F}}$ and $\mathrm{I}_{\mathrm{F}}$ correspond to the intensity of the main peak and the secondary peak. The variation of the crystallinity index $(\Delta C r I)$ was determined using Equation (2).

$$
\Delta(C r I) \%=\frac{C r I_{\mathcal{C}-C r I_{H}}}{C r I_{H}} \times 100
$$

where $\mathrm{CrI}_{\mathcal{C}}$ and $\mathrm{CrI}_{H}$ are crystallinity index values for copolymer and homopolymers, respectively [50].

The dry hydrogels also were analyzed by Fourier Transformed Infrared Spectroscopy (FTIR). The spectra in KBr pellets were obtained using a Spectrometer (Brucker OpticsVertex 70, Brucker, Billerica, MA, USA.) in a scanning range from 400 to $4000 \mathrm{~cm}^{-1}$ with 64 scans and $4 \mathrm{~cm}^{-1}$ resolution. Thermogravimetric analyses (TGA) were performed on an SDT Q600 (V20.9 Build 20, TA Instruments, New Castle, DE, USA.) instrument, using a heating rate of $10^{\circ} \mathrm{C} \mathrm{min}^{-1}\left(25\right.$ to $\left.650{ }^{\circ} \mathrm{C}\right)$, under argon atmosphere with $100 \mathrm{~mL} \mathrm{~min}{ }^{-1}$ in an alumina sample port. The morphological characteristics of the materials were analyzed by Field Emission Scanning Electron Microscopy (FESEM) equipment (QUANTA 250 FEI, FEI Company, Eindhoven, the Netherlands) coupled with elemental analysis by Energy Dispersive Spectroscopy (EDS) (EDAX Apollo X, FEI Company, Eindhoven, The Netherlands). The FESEM images were processed using Image J software.

\subsection{Swelling Tests}

\subsubsection{Determination of Swelling/Reswelling Capacity}

For swelling tests, $0.20 \mathrm{~g}$ of dry HCG and HCGP were immersed in $100.0 \mathrm{~mL}$ of distilled water, at an ambient temperature of $25^{\circ} \mathrm{C}\left( \pm 2^{\circ}\right)$. After the swelling was balanced, the swollen samples were removed from the medium and the excess water removed with filter paper. Then, the swelling ratio for each sample was determined according to Equation (3) [25]:

$$
\text { Swelling ratio }(\%)=\frac{W e-W o}{W o} \times 100
$$

where $W_{o}$ and $W_{e}$ correspond to the hydrogel weights before and after swelling, respectively.

To investigate the reusability of the HCG and HCGP hydrogels, the dry samples were immersed in water $(100 \mathrm{~mL})$ at room temperature for swelling equilibrium. The swollen hydrogels were weighed, and the swelling ratio was determined according to Equation (1). Then, the samples were dried at $50.0^{\circ} \mathrm{C}$ until they reached constant mass, and a next swelling experiment was performed. This procedure was repeated for up to 55 cycles to determine the reswelling capacity of the samples.

\subsection{2. $\mathrm{pH}$ Response}

To investigate the $\mathrm{pH}$ influence on the swelling tests of the samples, the hydrogels were swelled with buffer solution with $\mathrm{pH} 2,4,7,9$ or 12 . In each case, the water retention capacity was determined considering Equation (3).

\subsection{Fertilizer Release Experiment}

The controlled release of macronutrient phosphorus in the HCGP sample was performed using a colorimetric assay. For this, $0.20 \mathrm{~g}$ of HCGP sample was swelled under conditions similar to those described in the swelling tests. Then, $5.0 \mathrm{~mL}$ of the supernatant were removed and mixed with $100.0 \mathrm{~mL}$ of the extraction solution in Melich $(\mathrm{HCl}$ $0.05 \mathrm{~mol} \mathrm{~L}^{-1}$ and $\mathrm{H}_{2} \mathrm{SO}_{4} 0.0125 \mathrm{~mol} \mathrm{~L}^{-1}$ ), under mechanical stirring for $5 \mathrm{~min}$. Subsequently, a $25 \mathrm{~mL}$ aliquot was removed and $10 \mathrm{~mL}$ of ammonium molybdate solution was added to it. After this process, $30.0 \mathrm{mg}$ of ascorbic acid was added to the solution and stirred for about $2 \mathrm{~min}$; the system was left to rest for $60 \mathrm{~min}$. Then, aliquots were analyzed by the UV-Vis spectrophotometer at a wavelength of $660 \mathrm{~nm}$, and the release of the fertilizer was quantified [91]. 
To investigate the kinetics of fertilizer release from the HCGP hydrogel, the following mathematical models were considered: zero-order [22,92], first-order [22], Higuchi model [22], and Korsmeyer-Peppas model [22,93], as shown in Equations (4)-(7):

$$
\begin{gathered}
\text { Zero }- \text { order : }\left(\frac{M_{t}}{M_{\infty}}\right)=K t \\
\text { First }- \text { order : } \log \left(\frac{M_{t}}{M_{\infty}}\right)=\log K+n \log (t) \\
\text { Higuchi model : }\left(\frac{M_{t}}{M_{\infty}}\right)=K H_{t}^{\frac{1}{2}} \\
\text { Korsmeyer-Peppas model : }\left(\frac{M_{t}}{M_{\infty}}\right)=K t^{n}
\end{gathered}
$$

where $M_{t} / M_{\infty}$ corresponds to the fraction of fertilizer released at a certain time $(t), n$ is an indicator of nutrient release mechanism and $K$ represents the release kinetic constant.

\subsection{Texture Analysis}

The texture analysis of the hydrogels was performed using a Brookfield CT3 Texture Analyzer. The probe of the type TA-AACC 36 with a load of $5 \mathrm{~g}$ with a speed of $2 \mathrm{~mm} \mathrm{~s}^{-1}$ under a base of the type TA-BT-KIT was used during the test. The specimens were made using $0.20 \mathrm{~g}$ of hydrogels (dimension of $5.0 \mathrm{~cm} \times 4.0 \mathrm{~cm}$ ) in contact with $50.0 \mathrm{~mL}$ of deionized water for a period of $24 \mathrm{~h}$ at room temperature.

\subsection{Toxicity}

The toxicity of the HCG and HCGP samples was performed using Artemia salina, according to the methodology proposed by the literature. For this, microcrustacean larvae were hatched in $48 \mathrm{~h}$ under controlled lighting and oxygenation in a synthetic saline solution (12 ppm) composed of $15.153 \mathrm{~g}$ of $\mathrm{NaCl}, 1.398 \mathrm{~g}$ of $\mathrm{MgCl} 1.888 \mathrm{~g}$ of $\mathrm{MgSO}_{4}, 0.652 \mathrm{~g}$ of $\mathrm{CaCl}_{2}, 0.414 \mathrm{~g}$ of $\mathrm{KCl}$ and $0.116 \mathrm{~g}$ of $\mathrm{NaHCO}_{3}$ in $1.0 \mathrm{~L}$ of distilled water. Then, an amount of 10 live nauplii was collected and placed in contact with the aqueous extracts of HCG and HCGP in concentrations of $0.1,0.5,1.0$ and $5.0 \mu \mathrm{g} \mathrm{mL}{ }^{-1}$. During the tests, the systems were kept under controlled lighting conditions. After $24 \mathrm{~h}$ and $48 \mathrm{~h}$, the microcrustacean survival rate was determined. Synthetic saline was used as a negative control [94].

\section{Conclusions}

SAHs were synthesized from the grafting of CG polysaccharide with PAM. The XRD, FTIR and TGA techniques confirmed the formation of crosslink in the HCG and HCGP samples. The addition of the PHP fertilizer affected the crystallinity, morphology, swelling capacity and properties, such as hardness and adhesiveness, in the HCGP hydrogel. The increase in $\mathrm{pH}$ favored swelling due to the ionization of the hydrophilic groups present in the polymeric chain of the material. The sustained release of fertilizer occurred through a diffusion process, as confirmed by fit of the data to the Korsmeyer-Peppas model. In general, the HCG and HCGP materials demonstrated good swelling capacity in consecutive cycles, and the samples exhibited no toxicity. Finally, the results showed that HCGP is promising for use as a water reserve system and the controlled release of nutrients.

Author Contributions: Conceptualization, H.R.S. and I.S.L.; methodology, H.R.S., I.S.L., L.M.L.N. and A.S.S.; investigation, H.R.S., I.S.L., L.M.L.N. and A.S.S.; resources, E.C.S.-F. and R.F.R; writingoriginal draft preparation, H.R.S.; writing-review and editing, H.R.S., F.P.A., D.A.S., J.A.O., L.R.B. and A.M.S.S.N.; supervision, E.C.S.-F. and R.F.R; project administration, E.C.S.-F., J.A.O. and L.R.B.; funding acquisition, E.C.S.-F. All authors have read and agreed to the published version of the manuscript.

Funding: The research was by CNPq (Conselho Nacional de Desenvolvimento Científico e Tecnológico) grant number [441321/2017-8]. 
Data Availability Statement: The data presented in this study are available upon request to the author for correspondence.

Acknowledgments: The authors thank CAPES, CNPq, and UFPI, for financial and/or structural support.

Conflicts of Interest: The authors declare no conflict of interest.

Sample Availability: Samples of the all compounds are available from the authors.

\section{References}

1. Varaprasad, K.; Raghavendra, G.M.; Jayaramudu, T.; Yallapu, M.M.; Sadiku, R. A mini review on hydrogels classification and recent developments in miscellaneous applications. Mater. Sci. Eng. C 2017, 79, 958-971. [CrossRef]

2. Kapoor, S.; Kundu, S.C. Silk protein-based hydrogels: Promising advanced materials for biomedical applications. Acta Biomater. 2016, 31, 17-32. [CrossRef] [PubMed]

3. Heidarian, P.; Kouzani, A.Z.; Varley, R.; Kaynak, A.; Paulino, M.; Nasri-nasrabadi, B.; Zolfagharian, A. Dynamic plant-derived polysaccharide-based hydrogels. Carbohydr. Polym. 2021, 231, 1-47. [CrossRef] [PubMed]

4. Nie, J.; Pei, B.; Wang, Z.; Hu, Q. Construction of ordered structure in polysaccharide hydrogel: A review. Carbohydr. Polym. 2019, 205, 225-235. [CrossRef]

5. Dreiss, C.A. Hydrogel design strategies for drug delivery. Curr. Opin. Colloid Interface Sci. 2020, 48, 1-17. [CrossRef]

6. Ribeiro, A.J.; Lucena, F.R.; Souza, D.; Bezerra, J.M.N.A.; Oliveira, C.; Nadvorny, D.; La, M.F.D.; Soares, R.; Nunes, L.C.C.; Silva-filho, E.C.; et al. Gums' based delivery systems: Review on cashew gum and its derivatives. Carbohydr. Polym. 2016, 147, 188-200. [CrossRef] [PubMed]

7. Rodrigues, J.d.A.; de Araújo, A.R.; Pitombeira, N.A.; Plácido, A.; de Almeida, M.P.; Veras, L.M.C.; Delerue-Matos, C.; Lima, F.C.D.A.; Batagin Neto, A.; de Paula, R.C.M.; et al. Acetylated cashew gum-based nanoparticles for the incorporation of alkaloid epiisopiloturine. Int. J. Biol. Macromol. 2019, 128, 965-972. [CrossRef] [PubMed]

8. Warkar, S.G.; Kumar, A. Synthesis and assessment of carboxymethyl tamarind kernel gum based novel superabsorbent hydrogels for agricultural applications. Polymer 2019, 182, 121823.

9. Hajikhani, M.; Khanghahi, M.M.; Shahrousvand, M.; Mohammadi-Rovshandeh, J.; Babaei, A.; Khademi, S.M.H. Intelligent superabsorbents based on a xanthan gum/poly (acrylic acid) semi-interpenetrating polymer network for application in drug delivery systems. Int. J. Biol. Macromol. 2019, 139, 509-520. [CrossRef]

10. Ullah, F.; Othman, M.B.H.; Javed, F.; Ahmad, Z.; Akil, H.M. Classification, processing and application of hydrogels: A review. Mater. Sci. Eng. C 2015, 57, 414-433. [CrossRef]

11. Fajardo, A.R.; Fávaro, S.L.; Rubira, A.F.; Muniz, E.C. Dual-network hydrogels based on chemically and physically crosslinked chitosan/chondroitin sulfate. React. Funct. Polym. 2013, 73, 1662-1671. [CrossRef]

12. Graham, T. On the properties of silicic acid and other analogous colloidal substances. Proc. R. Soc. Lond. 1864, 13, 335-341. [CrossRef]

13. Hoffman, A.S. Hydrogels for biomedical applications. Adv. Drug Deliv. Rev. 2012, 64, 18-23. [CrossRef]

14. Peppas, N.A.; Bures, P.; Leobandung, W.; Ichikawa, H. Hydrogels in pharmaceutical formulations. Eur. J. Pharm. Biopharm. 2000, 50, 27-46. [CrossRef]

15. Drury, J.L.; Mooney, D.J. Hydrogels for tissue engineering: Scaffold design variables and applications. Biomaterials 2003, 24, 4337-4351. [CrossRef]

16. Tran, H.D.N.; Park, K.D.; Ching, Y.C.; Huynh, C.; Nguyen, D.H. A comprehensive review on polymeric hydrogel and its composite: Matrices of choice for bone and cartilage tissue engineering. J. Ind. Eng. Chem. 2020, 89, 58-82. [CrossRef]

17. Pereira, A.G.B.; Rodrigues, F.H.A.; Paulino, A.T.; Martins, A.F.; Fajardo, A.R. Recent advances on composite hydrogels designed for the remediation of dye-contaminated water and wastewater: A review. J. Clean. Prod. 2021, 284, 124703. [CrossRef]

18. Guilherme, M.R.; Aouada, F.A.; Fajardo, A.R.; Martins, A.F.; Paulino, A.T.; Davi, M.F.T.; Rubira, A.F.; Muniz, E.C. Superabsorbent hydrogels based on polysaccharides for application in agriculture as soil conditioner and nutrient carrier: A review. Eur. Polym. J. 2015, 72, 365-385. [CrossRef]

19. Rizwan, M.; Syeda, P.; Gilani, R.; Iqbal, A. Materials diversity of Hydrogel: Synthesis, polymerization process and soil conditioning properties in agricultural field. J. Adv. Res. 2021, in press. [CrossRef]

20. Głowińska, A.; Trochimczuk, A.W.; Jakubiak-Marcinkowska, A. Novel acrylate/organophosphorus-based hydrogels for agricultural applications. New outlook and innovative concept for the use of 2-(methacryloyloxy)ethyl phosphate as a multi-purpose monomer. Eur. Polym. J. 2019, 110, 202-210. [CrossRef]

21. Chen, J.; Lü, S.; Zhang, Z.; Zhao, X.; Li, X.; Ning, P.; Liu, M. Environmentally friendly fertilizers: A review of materials used and their effects on the environment. Sci. Total Environ. 2018, 613, 829-839. [CrossRef]

22. Rozo, G.; Bohorques, L.; Santamaría, J. Controlled release fertilizer encapsulated by a k-carrageenan hydrogel. Polimeros 2019, 29, 2-8. [CrossRef]

23. Corradini, E.; de Moura, M.R.; Mattoso, L.H.C. A preliminary study of the incorparation of NPK fertilizer into chitosan nanoparticles. Express Polym. Lett. 2010, 4, 509-515. [CrossRef]

24. Li, X.; Li, Q.; Su, Y.; Yue, Q.; Gao, B.; Su, Y. A novel wheat straw cellulose-based semi-IPNs superabsorbent with integration of water-retaining and controlled-release fertilizers. J. Taiwan Inst. Chem. Eng. 2015, 55, 170-179. [CrossRef] 
25. Tanan, W.; Panichpakdee, J.; Saengsuwan, S. Novel biodegradable hydrogel based on natural polymers: Synthesis, characterization, swelling/reswelling and biodegradability. Eur. Polym. J. 2019, 112, 678-687. [CrossRef]

26. Bashir, S.; Hina, M.; Iqbal, J.; Rajpar, A.H.; Mujtaba, M.A.; Alghamdi, N.A.; Wageh, S.; Ramesh, K.; Ramesh, S. Fundamental concepts of hydrogels: Synthesis, properties, and their applications. Polymers 2020, 12, 2702. [CrossRef] [PubMed]

27. Da Silva, D.A.; de Paula, R.C.M.; Feitosa, J.P.A. Graft copolymerisation of acrylamide onto cashew gum. Eur. Polym. J. 2007, 43, 2620-2629. [CrossRef]

28. Chang, L.; Xu, L.; Liu, Y.; Qiu, D. Superabsorbent polymers used for agricultural water retention. Polym. Test. 2021, $94,107021$. [CrossRef]

29. Ghobashy, M.M.; El-Damhougy, B.K.; Nady, N.; El-Wahab, H.A.; Naser, A.M.; Abdelhai, F. Radiation Crosslinking of Modifying Super Absorbent (Polyacrylamide/Gelatin) Hydrogel as Fertilizers Carrier and Soil Conditioner. J. Polym. Environ. 2018, 26, 3981-3994. [CrossRef]

30. Mahinroosta, M.; Jomeh Farsangi, Z.; Allahverdi, A.; Shakoori, Z. Hydrogels as intelligent materials: A brief review of synthesis, properties and applications. Mater. Today Chem. 2018, 8, 42-55. [CrossRef]

31. Jeong, D.; Kim, C.; Kim, Y.; Jung, S. Dual crosslinked carboxymethyl cellulose/polyacrylamide interpenetrating hydrogels with highly enhanced mechanical strength and superabsorbent properties. Eur. Polym. J. 2020, 127, 109586. [CrossRef]

32. Thakur, S.; Arotiba, O.A. Synthesis, swelling and adsorption studies of a pH-responsive sodium alginate-poly (acrylic acid) superabsorbent hydrogel. Polym. Bull. 2018, 75, 4587-4606. [CrossRef]

33. Fang, S.; Wang, G.; Xing, R.; Chen, X.; Liu, S.; Qin, Y.; Li, K.; Wang, X.; Li, R.; Li, P. Synthesis of superabsorbent polymers based on chitosan derivative graft acrylic acid-co-acrylamide and its property testing. Int. J. Biol. Macromol. 2019, 132, 575-584. [CrossRef]

34. Ahmad, S.; Ahmad, M.; Manzoor, K.; Purwar, R.; Ikram, S. A review on latest innovations in natural gums based hydrogels: Preparations \& applications. Int. J. Biol. Macromol. 2019, 136, 870-890.

35. Padil, V.V.T.; Wacławek, S.; Černík, M.; Varma, R.S. Tree gum-based renewable materials: Sustainable applications in nanotechnology, biomedical and environmental fields. Biotechnol. Adv. 2018, 36, 1984-2016. [CrossRef]

36. Rana, V.; Rai, P.; Tiwary, A.K.; Singh, R.S.; Kennedy, J.F.; Knill, C.J. Modified gums: Approaches and applications in drug delivery. Carbohydr. Polym. 2011, 83, 1031-1047. [CrossRef]

37. Hasija, V.; Sharma, K.; Kumar, V.; Sharma, S.; Sharma, V. Green synthesis of agar/Gum Arabic based superabsorbent as an alternative for irrigation in agriculture. Vacuum 2018, 157, 458-464. [CrossRef]

38. Behrouzi, M.; Moghadam, P.N. Synthesis of a new superabsorbent copolymer based on acrylic acid grafted onto carboxymethyl tragacanth. Carbohydr. Polym. 2018, 202, 227-235. [CrossRef]

39. Sharma, K.; Kumar, V.; Chaudhary, B.; Kaith, B.S.; Kalia, S.; Swart, H.C. Application of biodegradable superabsorbent hydrogel composite based on Gum ghatti-co-poly (acrylic acid-aniline) for controlled drug delivery. Polym. Degrad. Stab. 2016, 124, 101-111. [CrossRef]

40. Guilherme, M.R.; Reis, A.V.; Feitosa, J.P.A.; Muniz, E.C. Synthesis of a novel superabsorbent hydrogel by copolymerization of acrylamide and cashew gum modified with glycidyl methacrylate. Carbohydr. Polym. 2005, 61, 464-471. [CrossRef]

41. Klein, J.M.; Silva de Lima, V.; Couto da Feira, J.M.; Nichele Brandalise, R.; de Camargo Forte, M.M. Chemical modification of cashew gum with acrylamide using an ultrasound-assisted method. J. Appl. Polym. Sci. 2016, 133, 1-12. [CrossRef]

42. Raquel, S.; Vitória, M.; Mesquita, N.; Sá, L.L.; Nogueira, N.C.; Rizzo, M.S.; Silva-Filho, E.C.; Costa, M.P.; Ribeiro, A.B. Sustainable natural gums for industrial application: Physiochemical and texturometric evaluation. J. Drug Deliv. Sci. Technol. 2019, 54, 101306.

43. Paula, R.C.M.D.; Heatley, F.; Budd, P.M. Characterization of Anacardium occidentale Exudate Polysaccharide. Polym. Int. 1998, 45, 27-35. [CrossRef]

44. Moreira, B.R.; Pereira-Júnior, M.A.; Fernandes, K.F. An ecofriendly edible coating using cashew gum polysaccharide and polyvinyl alcohol. Food Biosci. 2021, 37, 1-31. [CrossRef]

45. Amorim, D.R.B.; da Silva Guimarães, I.; Fugikawa-Santos, L.; Vega, M.L.; da Cunha, H.N. Effect of temperature on the electrical conductivity of polyaniline/cashew gum blends. Mater. Chem. Phys. 2020, 253, 123383. [CrossRef]

46. Guilherme, M.R.; Campese, G.M.; Radovanovic, E.; Rubira, A.F.; Feitosa, J.P.A.; Muniz, E.C. Morphology and water affinity of superabsorbent hydrogels composed of methacrylated cashew gum and acrylamide with good mechanical properties. Polymer 2005, 46, 7867-7873. [CrossRef]

47. Silva, M.C.C.; Santos, M.S.F.; Bezerra, R.D.S.; Araújo-Júnior, E.A.; Osajima, J.A.; Santos, M.R.M.C.; Fonseca, M.G.; Silva-Filho, E.C. Kaolinite/cashew gum bionanocomposite for doxazosin incorporation and its release. Int. J. Biol. Macromol. 2020, 161, 927-935. [CrossRef]

48. Prusty, K.; Biswal, A.; Biswal, S.B.; Swain, S.K. Synthesis of soy protein/polyacrylamide nanocomposite hydrogels for delivery of ciprofloxacin drug. Mater. Chem. Phys. 2019, 234, 378-389. [CrossRef]

49. Azzam, E.M.S.; El-Salam, H.M.A.; Mohamed, R.A.; Shaban, S.M.; Shokry, A. Control the corrosion of mild steel using synthesized polymers based on polyacrylamide. Egypt. J. Pet. 2018, 27, 897-910. [CrossRef]

50. Ilić-Stojanović, S.; Nikolić, L.; Nikolić, V.; Petrović, S.; Oro, V.; Mitić, Ž.; Najman, S. Semi-Crystalline Copolymer Hydrogels as Smart Drug Carriers: In Vitro Thermo-Responsive Naproxen Release Study. Pharmaceutics 2021, 13, 158. [CrossRef]

51. Saragih, S.W.; Wirjosentono, B.; Meliana, Y. Influence of crosslinking agent on the morphology, chemical, crystallinity and thermal properties of cellulose nanofiber using steam explosion. Case Stud. Therm. Eng. 2020, 22, 100740. [CrossRef] 
52. Silva, E.L.V.; Oliveira, A.C.J.; Patriota, Y.B.G.; Ribeiro, A.J.; Veiga, F.; Hallwass, F.; Silva, E.C.; Filho; Silva, D. A.; Soares, M.F.d.L.R.; Wanderley, A.G.; et al. Solvent-free synthesis of acetylated cashew gum for oral delivery system of insulin. Carbohydr. Polym. 2019, 207, 601-608. [CrossRef] [PubMed]

53. Hamidreza, S.; Hazbavi, Z.; Younesi, H.; Bahramifar, N. Trade-off between runoff and sediments from treated erosion plots and polyacrylamide and acrylamide residues. Catena 2016, 142, 213-220.

54. Thombare, N.; Mishra, S.; Siddiqui, M.Z.; Jha, U.; Singh, D.; Mahajan, G.R. Design and development of guar gum based novel, superabsorbent and moisture retaining hydrogels for agricultural applications. Carbohydr. Polym. 2018, 185, 169-178. [CrossRef]

55. Jayaramudu, T.; Ko, H.U.; Kim, H.C.; Kim, J.W.; Kim, J. Swelling behavior of polyacrylamide-cellulose nanocrystal hydrogels: Swelling kinetics, temperature, and $\mathrm{pH}$ effects. Materials 2019, 12, 2080. [CrossRef]

56. Bal, T.; Yadav, S.K.; Rai, N.; Swain, S.; Garg, S.; Sen, G. Invitro evaluations of free radical assisted microwave irradiated polyacrylamide grafted cashew gum (CG) biocompatible graft copolymer (CG-g-PAM) as effective polymeric scaffold. J. Drug Deliv. Sci. Technol. 2020, 56, 101572. [CrossRef]

57. Ferreira, M.O.G.; Lima, I.S.; Ribeiro, A.B.; Lobo, A.O.; Rizzo, M.S.; Osajima, J.A.; Estevinho, L.M.; Silva-Filho, E.C. Biocompatible Gels of Chitosan-Buriti Oil for Potential Wound Healing Applications. Materials 2020, 13, 1977. [CrossRef]

58. Cai, T.; Yang, Z.; Li, H.; Yang, H.; Li, A.; Cheng, R. Effect of hydrolysis degree of hydrolyzed polyacrylamide grafted carboxymethyl cellulose on dye removal efficiency. Cellulose 2013, 20, 2605-2614. [CrossRef]

59. Wang, Y.; Tong, L.; Zheng, Y.; Pang, S.; Sha, J.; Li, L. Hydrogels with self-healing ability, excellent mechanical properties and biocompatibility prepared from oxidized gum arabic. Eur. Polym. J. 2019, 117, 363-371. [CrossRef]

60. Oliveira, A.C.d, J; Chaves, L.L.; Ribeiro, F.D.O.S.; de Lima, L.R.M.; Oliveira, T.C.; García-Villén, F.; Viseras, C.; de Paula, R.C.M.; Rolim-Neto, P.J.; Hallwass, F.; et al. Microwave-initiated rapid synthesis of phthalated cashew gum for drug delivery systems. Carbohydr. Polym. 2021, 254, 117226. [CrossRef]

61. Zhang, X.; Han, M.; Fuseni, A.; Alsofi, A.M. An approach to evaluate polyacrylamide-type polymers' long-term stability under high temperature and high salinity environment. J. Pet. Sci. Eng. 2019, 180, 518-525. [CrossRef]

62. Haseeb, M.T.; Hussain, M.A.; Yuk, S.H.; Bashir, S.; Nauman, M. Polysaccharides based superabsorbent hydrogel from Linseed: Dynamic swelling, stimuli responsive on-off switching and drug release. Carbohydr. Polym. 2016, 136, 750-756. [CrossRef] [PubMed]

63. Bai, H.; Li, Z.; Zhang, S.; Wang, W.; Dong, W. Interpenetrating polymer networks in polyvinyl alcohol/cellulose nanocrystals hydrogels to develop absorbent materials. Carbohydr. Polym. 2018, 200, 468-476. [CrossRef] [PubMed]

64. Meng, Y.; Liu, X.; Li, C.; Liu, H.; Cheng, Y.; Lu, J.; Zhang, K.; Wang, H. Super-swelling lignin-based biopolymer hydrogels for soil water retention from paper industry waste. Int. J. Biol. Macromol. 2019, 135, 815-820. [CrossRef]

65. Liu, C.; Lei, F.; Li, P.; Jiang, J.; Wang, K. Borax crosslinked fenugreek galactomannan hydrogel as potential water-retaining agent in agriculture. Carbohydr. Polym. 2020, 236, 116100. [CrossRef]

66. Chen, M.; Ni, Z.; Shen, Y.; Xiang, G.; Xu, L. Reinforced swelling and water-retention properties of super-absorbent hydrogel fabricated by a dual stretchable single network tactic. Colloids Surf. A Physicochem. Eng. Asp. 2020, 602, 125133. [CrossRef]

67. Cao, L.; Li, N. Activated-carbon-filled agarose hydrogel as a natural medium for seed germination and seedling growth. Int. J. Biol. Macromol. 2021, 177, 383-391. [CrossRef]

68. Olad, A.; Doustdar, F.; Gharekhani, H. Fabrication and characterization of a starch-based superabsorbent hydrogel composite reinforced with cellulose nanocrystals from potato peel waste. Colloids Surf. A Physicochem. Eng. Asp. 2020, 601, 124962. [CrossRef]

69. Chang, C.; Duan, B.; Cai, J.; Zhang, L. Superabsorbent hydrogels based on cellulose for smart swelling and controllable delivery. Eur. Polym. J. 2010, 46, 92-100. [CrossRef]

70. Yan, S.; Wu, Y.; Fan, J.; Zhang, F.; Zheng, J. Dynamic change and accumulation of grain macronutrient (N, P and K) concentrations in winter wheat under different drip fertigation regimes. Field Crop. Res. 2020, 250, 107767. [CrossRef]

71. Alharbi, K.; Ghoneim, A.; Ebid, A.; El-Hamshary, H.; El-Newehy, M.H. Controlled release of phosphorous fertilizer bound to carboxymethyl starch- g -polyacrylamide and maintaining a hydration level for the plant. Int. J. Biol. Macromol. 2018, 116, $224-231$. [CrossRef]

72. Bennour, S.; Louzri, F. Study of Swelling Properties and Thermal Behavior of Poly (N, N-Dimethylacrylamide- co -Maleic Acid) Based Hydrogels. Adv. Chem. 2014, 2014, 1-10. [CrossRef]

73. Baki, M.; Abedi-Koupai, J. Preparation and characterization of a superabsorbent slow-release fertilizer with sodium alginate and biochar. J. Appl. Polym. Sci. 2018, 135, 45966. [CrossRef]

74. Wu, L.; Liu, M.; Liang, R. Preparation and properties of a double-coated slow-release NPK compound fertilizer with superabsorbent and water-retention. Bioresour. Technol. 2008, 99, 547-554. [CrossRef]

75. Dwivedi, R.; Singh, A.K.; Dhillon, A. pH-responsive drug release from dependal-M loaded polyacrylamide hydrogels. J. Sci. Adv. Mater. Devices 2017, 2, 45-50. [CrossRef]

76. Soni, G.; Yadav, K.S. High encapsulation efficiency of poloxamer-based injectable thermoresponsive hydrogels of etoposide. Pharm. Dev. Technol. 2014, 19, 651-661. [CrossRef] [PubMed]

77. Sung, Y.; Kim, T.H.; Lee, B. Syntheses of carboxymethylcellulose/graphene nanocomposite superabsorbent hydrogels with improved gel properties using electron beam radiation. Macromol. Res. 2016, 24, 143-151. [CrossRef] 
78. Li, Z.; Wang, D.; Bai, H.; Zhang, S.; Ma, P.; Dong, W. Photo-Crosslinking Strategy Constructs Adhesive, Superabsorbent, and Tough PVA-Based Hydrogel through Controlling the Balance of Cohesion and Adhesion. Macromol. Mater. Eng. 2020, 305, 1-8. [CrossRef]

79. Singh, V.; Tiwari, A.; Narayan, D.; Sanghi, R. Microwave enhanced synthesis of chitosan- graft -polyacrylamide. Polymer 2006, 47, 254-260. [CrossRef]

80. Sharma, B.R.; Kumar, V.; Soni, P.L. Ceric Ammonium Nitrate-Initiated Graft Copolymerization of Acrylamide onto Cassia tora Gum. J. Appl. Polym. Sci. 2002, 86, 3250-3255. [CrossRef]

81. Mahdavinia, G.R.; Pourjavadi, A. Modified chitosan from poly (acrylic acid-co-acrylamide) grafted chitosan with salt- and pH-responsiveness properties. Eur. Polym. J. 2004, 40, 1399-1407. [CrossRef]

82. Borba, F.H.; Leichtweis, J.; Bueno, F.; Pellenz, L.; Inticher, J.J. Pollutant removal and acute toxicity assessment (Artemia salina) of landfill leachate treated by photo-Fenton process mediated by oxalic acid. J. Water Process Eng. 2019, 28, 159-168. [CrossRef]

83. Vinicius, M.; Bastos, L.; Rocha, N.; Acelina, M.; Carvalho, M.D.; Osajima, J.A.; Silva-Filho, E.C. Development of Composite Scaffolds Based on Cerium Doped-Hydroxyapatite and Natural Gums-Biological and Mechanical Properties. Materials 2019, 12, 2389. [CrossRef] [PubMed]

84. Li, W.W.; Hui, L.; Liu, Z.F.; Qun, Q. Determination of residual acrylamide in medical polyacrylamide hydrogel by high performance liquid chromatography tandem mass spectroscopy. Biomed. Environ. Sci. 2009, 22, 28-31. [CrossRef]

85. Madhav, M.R.; David, S.E.M.; Kumar, R.S.S.; Swathy, J.S.; Bhuvaneshwari, M.; Mukherjee, A.; Chandrasekaran, N. Toxicity and accumulation of Copper Oxide (CuO) Nanoparticles in different life stages of Artemia salina. Environ. Toxicol. Pharmacol. 2017, 52, 227-238. [CrossRef]

86. Araujo, F.P.; Trigueiro, P.; Honório, L.M.C.; Oliveira, D.M.; Almeida, L.C.; Garcia, R.P.; Lobo, A.O.; Cantanhêde, W.; Silva-Filho, E.C.; Osajima, J.A. Eco-friendly synthesis and photocatalytic application of flowers-like ZnO structures using Arabic and Karaya Gums. Int. J. Biol. Macromol. 2020, 165, 2813-2822. [CrossRef]

87. Nunes, B.S.; Carvalho, F.D.; Guilhermino, L.M.; Van Stappen, G. Use of the genus Artemia in ecotoxicity testing. Environ. Poll. 2006, 144, 453-462. [CrossRef]

88. Mu, B.; Wang, A. Adsorption of dyes onto palygorskite and its composites: A review. J. Environ. Chem. Eng. 2016, 4, 1274-1294. [CrossRef]

89. Lira, L.M.; Martins, K.A.; Torresi, S.I.C. Structural parameters of polyacrylamide hydrogels obtained by the Equilibrium Swelling Theory. Eur. Polym. J. 2009, 45, 1232-1238. [CrossRef]

90. Rodrigues, J.F.; Paula, R.C.M.D.; Costa, S.M.O. Métodos de Isolamento de Gomas Naturais: Comparação Através da Goma do Cajueiro (Anacardium occidentale L). Polim. Ciência E Tecnol. 1993, 31-36.

91. Teixeira, P.C.; Donagemma, G.K.; Fontana, A.; Teixeira, W.G. Manual de métodos de análises de solos (3a.); Embrapa: Brasilia, Brazil, 2017; ISBN 9788570357717.

92. Elving, P.J.; Markowitz, J.M.; Rosenthal, I. Preparation of buffer systems of constant ionic strength. Anal. Chem. 1956, 28, 1179-1180. [CrossRef]

93. Ritger, P.L.; Peppas, N.A. A simple equation for description of solute release i. Fickian and non-fickian release from non-swellable devices in the form of slabs, spheres, cylinders or discs. J. Control. Release 1987, 5, 23-36. [CrossRef]

94. Meyer, B.N.; Ferrigni, N.R.; Putnam, J.E.; Jacobsen, L.B.; Nichols, D.E.; McLaughin, J.L. Brine Shrimp: A Convenient General Bioassay for Active Plant Constituents. J. Med. Plant Res. 1982, 45, 31-34. [CrossRef] [PubMed] 